\title{
Introduction au dossier critique : territoire féminin dans l'œuvre de Claude Simon
}

\section{Anne-Yvonne Julien}

\section{(2) OpenEdition}

\section{Journals}

Édition électronique

URL : http://journals.openedition.org/ccs/851

DOI : 10.4000/ccs.851

ISSN : 2558-782X

Éditeur :

Presses universitaires de Rennes, Association des lecteurs de Claude Simon

\section{Édition imprimée}

Date de publication : 31 mars 2013

Pagination : 21-24

ISBN : 9782354121785

ISSN : $1774-9425$

\section{Référence électronique}

Anne-Yvonne Julien, « Introduction au dossier critique : territoire féminin dans l'œuvre de Claude Simon », Cahiers Claude Simon [En ligne], 8| 2013, mis en ligne le 21 septembre 2017, consulté le 24 septembre 2020. URL : http://journals.openedition.org/ccs/851 ; DOI : https://doi.org/10.4000/ccs. 851 
Territoires féminins dans l'œuvre de Claude Simon... Oui, le pluriel s'impose, et un pluriel qui dit la mobilité, la toujours imminente et potentielle métamorphose du féminin au long de tous ces textes.

D'abord parce que les silhouettes de femmes, souvent associées à tel ou tel souvenir des narrateurs des romans de Simon, renvoient à tous les âges de la vie. Quelques trop rapides exemples : «l'animal sauvage de la première apparition » (Le Sacre du Printemps ${ }^{1}$ ), "la serveuse allant et venant " $\left(V^{2}\right.$, p. 69), la «fille-garçon » $(V$, p. 82), «les deux gamines » $(V, \mathrm{p} .46)$, les « femmes jacassantes » se rencontrant à la fontaine " $(V, \mathrm{p} .53)$, la «fragile silhouette noire dans la lumière» (Hist., p. 27), «la bossue » (Hist., p. 110), «(les deux jeunes filles, les deux amies) " (Hist. p. 167), «Une brochette de vieilles dames aux toilettes voyantes " $(C C$, p. 28$)$, « la paysanne au visage brûlé par les étés, les hivers " $(G$, p. 408), « les trois femmes traînant avec elles le jeune garçon " (A, p. 73), "la jeune putain brune " (JP, p. 57), « des jeunes filles assises en tailleur, drapées dans des saris aux couleurs de fleurs et de fruits » $(J P$, p. 125$)$ « Une femme aux formes monstrueuses ", $(J P$, p. 223)...

1. Claude Simon, Le Sacre du printemps, éd. Calmann-Levy, 1954, p. 29.

2. Toutes les références de pages de romans (titres donnés sous forme abrégée) sont empruntées à l'édition originale Minuit. 
Ensuite parce que ces présences s'accompagnent d'un vraie cohorte de doubles mythiques : Phèdre, Déjanire, Pomone, Junon, Méduse, Vénus, Psyché, "Phrynés vêtues de robes transparentes " ( $G$, p. 249), Briséis, Omphale... Et qui pourrait nier que la femme ne s'affirme ici métonymiquement tant l'œuvre tend à blasonner le corps féminin : n'est-il pas loisible de voir dans La Chevelure de Bérénice, initialement intitulé Femmes, rêverie sur le monde luimême charnel et mythologique de Miro, une sorte de condensé de ce qui se joue à l'échelle de l'ensemble de l'œuvre ${ }^{3}$ ? Tout se résout en une vision marine et nocturne où « la tache laiteuse [des] cuisses » de la femme aperçue sur la plage est relayée par « la frange d'écume ondulant molle sans bruit ${ }^{4}$. Or qui dit blason poétique dit métamorphose continuée. Tant de paysages simoniens sont aussi ardeurs sensuelles, tant de visions de rues ou de coins d'appartement ou d'atelier se donnent comme clichés intimes. La contiguïté opère et la réversibilité s'assume... Inlassablement, l'œuvre revient sur l'énigme du désir, l'attraction des corps, leur rapprochement, leur entremêlement, leurs mêlées exténuantes et exténuées, leur langage jusque dans ses manifestations les plus crues, mais cette énigme est aussi celle de la vie, et elle s'élève à la dimension cosmique. C'est dire que la question du féminin est l'une des entrées possibles en territoire simonien, et non des moindres.

Il importait de faire retour sur les études critiques qui ont abordé la représentation des femmes et la question du féminin dans l'œuvre de Simon. Alastair Duncan s'y attache et dégage, dans ce corpus, trois directions principales. D'abord, un ensemble d'analyses qui, travaillant sur les composantes du monde romanesque de Simon, remarque que la femme apparaît toujours plus ou moins comme un « autre fondamental " face au groupe des hommes, ou dans la perspective du sujet narrateur - perspective clairement commentée par une part de la critique féministe. Ensuite, un recentrement sur

3. Claude Simon, La Chevelure de Bérénice, dans Euvres, Paris, Gallimard, "Bibliothèque de la Pléiade ", 2006, p. 551-564.

4. Claude Simon, ibid., p. 563. Voir l'étude de G. Zuccarino, "La plage. Les étoiles. Simon et l'Éros cosmique ", dans Cahiers Claude Simon n 7, p. 79-93. 
l'approche psychanalytique qui voit le féminin comme une projection des fantasmes du sujet masculin. A été fondatrice sur ce plan l'analyse de Lucien Dällenbach 5 , qui avait postulé la direction matrilinéaire du roman simonien, bâtie autour d'une absence de figure paternelle et multipliant les figures de pères de substitution. D'autres études ont poursuivi dans ce sens, s'intéressant à telle ou telle configuration œedipienne dans des textes spécifiques. Enfin, une série d'analyses qui montre, à l'épreuve du détail textuel, une instabilité des traits du masculin et du féminin, voire une réversibilité des champs qui met en déroute toute stéréotypie. Quelques pistes d'études sont tracées du côté de la considération des valeurs associées au masculin et au féminin et de leur évolution dans l'œuvre, ou d'une interrogation plus philosophique sur la manière dont l'écrivain conçoit le rapport entre sexualité et existence. (U. Stirling)

Michel Bertrand voit dans L'Herbe (1958) un hapax dans l'univers de Simon par le fait que sont mises à l'avant-scène du roman trois femmes, le trio Louise, Sabine, Marie - trois âges de la vie - alors que dans l'œuvre antécédente et ultérieure, les rôles principaux sont plutôt interprétés par des hommes. Sur le plan dramatique, tout repose en quelque sorte sur le lien qui, à l'occasion de l'agonie de Marie, se confirme entre Louise, la jeune épouse insatisfaite de Georges, en instance d'émancipation et cette vieille femme qui quitte l'existence et lègue à la jeune femme ses petits riens. Or c'est ce rapport de filiation inédit qui rend possible le récit de vie de Marie. Sabine, la mère de Georges, jalouse de la jeunesse de l'une et de la sérénité de l'autre, est l'élément exclu, soudant le duo jeune femme/vieille femme qui se renforce du refus commun des valeurs familiales ou conjugales de tradition. Si l'on passe sur le plan de la symbolique féminine, il semble que Marie et Sabine, s'ingénient l'une et l'autre avec des moyens quasiment opposés, à retenir Louise sur le domaine agricole, à la reinsérer dans le temps de la longue durée, elle que la modernité urbaine séduisait. Mais le roman peut être lu aussi comme une transposition, à travers la figure de Marie, de la longue agonie maternelle, si souvent évoquée par

5. Lucien Dällenbach, Claude Simon, «Les contemporains », Seuil,1988. 
les narrateurs masculins d'autres textes de Simon, certains motifs récurrents permettant d'en faire l'hypothèse. Le roman n'est peutêtre pas aussi féminin qu'il le paraît. (U. de Provence)

La Route des Flandres (1960) est sans doute l'un des romans simoniens où s'énonce le plus subtilement le sens que l'auteur accorde à l'écriture de la sexualité. Nathalie Piegay-Gros s'interroge sur les divers moments de cette scène de l'éros et sur ses implications. Il apparaît que le dire du sexe, non seulement dynamite le romanesque de l'amour, mais encore qu'il compromet toute stabilité de représentation, au même titre sans doute que le souvenir de l'épreuve guerrière. Loin d'apparaittre comme une occasion de résolution des conflits, l'expérience sexuelle - fantasme ou mémoire de l'étreinte se donne comme primitive, à la lisière de la folie, redoublant la violence de choc de la guerre, opérant une perturbation massive du cours du temps, dont effets de montage textuel et calembours, parfois délibérément vulgaires, visent à rendre compte. Les figurations $\mathrm{du}$ sexe féminin et du sexe masculin se trouvent très fortement marquées par l'animalité et l'imaginaire collectif se voit sollicité par le détour de la référence mythologique qui tend à tordre l'antique vers l'archaïque. Le sexe n'est pas non plus pour Claude Simon un espace d'identification de l'être humain : Corinne ne mène d'ailleurs pas Georges à Reixach ou à l'énigme de sa mort, le corps désiré de la femme est simplement censé dispenser à l'autre une énergie libidinale à la source de laquelle s'alimente la mémoire, image peutêtre de l'inlassable reprise de l'écriture. (U. Paris Diderot) 